\title{
XI. Note on a new form of vacuum stopcock
}

\section{S.R. Milner D.Sc.}

To cite this article: S.R. Milner D.Sc. (1903) XI. Note on a new form of vacuum stopcock, Philosophical Magazine Series 6, 6:31, 78-80, DOI: 10.1080/14786440309462992

To link to this article: http://dx.doi.org/10.1080/14786440309462992

册 Published online: 15 Apr 2009.

Submit your article to this journal $\pi$

Џll Article views: 2

Q View related articles $₫$ 
near enough), the vessel of $630 \mathrm{c}$ c. holds $9 \times 10^{-5} \mathrm{grs}$. of mercury. This is spread into a film of $11 \mathrm{sq}$. cms. Thus the thickness of the film is $6 \times 10^{-8}$. It was estimated that this film transmitted about $\frac{1}{5}$ of the light of the paraffin lamp. The transmitted light had a neutral tint.

The coefficient of absorption of solid mercury calculated from these data comes out $3 \times 10^{7}$.

In order to make a fair comparison between the vapour and the solid, the greater density of the latter must be allowed for. By dividing the coefficients of absorption by the respective densities, we get numbers by which the absorptions of equal masses of material in the two states can be compared.

For the vapour the $\frac{\text { coefficient of absorption }}{\text { density }}$ is less than 08 .

For the solid, this constant has a value of something like $2 \times 10^{6}$.

Thus, if we suppose the intensity of a beam of light to be diminished in a given ratio by passing through a film of solid mercury, then a stratum of mercury vapour containing not less (and perhaps much more) than $2 \times 10^{7}$ times the mass of mercury per sq. $\mathrm{cm}$. would be required to produce the same effect.

XI. Note on a New Form of Vacuum Stopcock. By S. R. Milner, D.Sc., Lecturer in Physics, University College, Sheffield*.

\begin{abstract}
A obvious defect of the ordinary form of mercury-sealed A stopcock is that with it, although the interior of the apparatus to which it is connected is sealed off by mercury from the atmosphere, there is no mercury sealing between the two portions of the apparatus joined by the stopcock; yet this is, in the usual form of stopcock, the route by which a leak is most likely to take place. The only way of removing this defect with which I am acquainted is the somewhat inconvenient one of using a movable reservoir by which mercury can be let into or out of one of the connecting-tubes to the stopcock. To obviate the necessity for this addition in a case where special airtightness of the tap was desired, I have recently made use of a form of stopcock which interposes a mercury sealing to the entrance of air into the apparatus by every route along which a leak might take place.
\end{abstract}

* Communicated by the Author. 
A reference to the figure, which shows a section of the barrel $x$ and the plug $y$ of the stopcock in position, will make its action clear without much description, The barrel is inclined to the horizontal at an angle of about $45^{\circ}$, and, in the position of the plug figured, a through connexion exists between the tubes $A$ and $B$. When the plug is turned through $180^{\circ}$, the separate portions of mercury $m_{1}, m_{2}, m_{3}$ seal off $B$ both from the atmosphere and from $A$. C is a

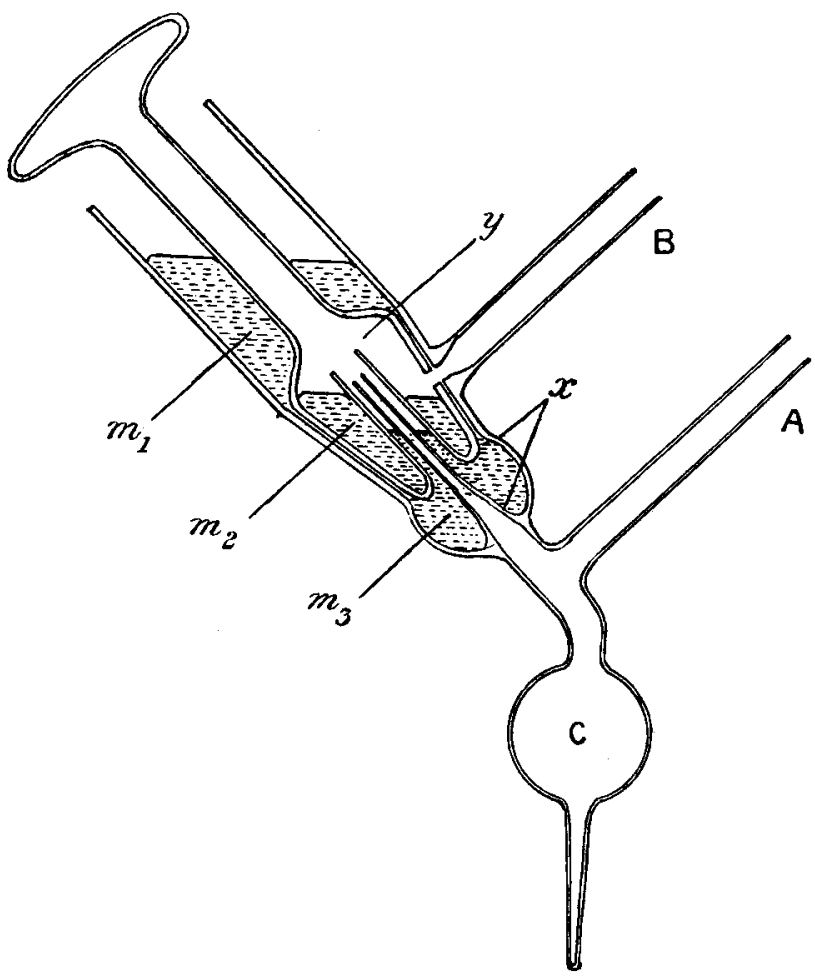

trap to catch any excess of the mercury $m_{3}$. It may be worth while to note that the stopcock should be ground fairly conical in shape, as, if there is a vacuum in $\mathbf{A}$, the plug is forced into the barrel by the whole atmospheric pressure; also, that there is a true mercury sealing only in the direction from $A$ to $B$, so that the apparatus into which it is desired to prevent leakage should be connected to this latter tube.

To get some idea of the extent to which a stopcock of this 


\section{Mr. Richardson on the Positive Ionization produced}

form would prevent leakage, I evacuated a tube onto which the stopcock was sealed, and, after allowing a couple of days for air condensed on the glass to escape, sealed it off from the pump at a stage at which the Crookes dark space just extended to the end of the tube $(20 \mathrm{cms}$.), and a bright green fluorescence of the glass was obtained throughout. After a week's exposure to leakage from the atmosphere through the stopcock, I could detect only a trace of blue coloration near the further end of the tube, indicating a diminution of two or three centimetres only in the length of the dark space. It is possible that some at any rate of the effect was due to further escape of air from the glass (which had not been heated during the evacuation), but in any case it is evident that the leakage through the stopcock was extremely minute. When the mercury $m_{1}$ was removed, the vacuum fell off at the rate of several cms. per day.

XII. On the Positive Ionization produced by Hot Platinum in Air at Low Pressures. By O. W. Richardson, B.A., B.Sc., Fellow of Trinity College, Cambridge* .

[Plate V.]

THE experiments to be described were originally undertaken in order to examine the connexion between the leak from a hot wire, when charged positively and surrounded by air, at a low pressure, and the potential and temperature of the wire respectively.

The arrangement of apparatus at first used was similar to that employed by the author in investigating the negative leak from hot conductors $t$. The wire, which was in the form of a spiral, was supported along the axis of a cylindrical electrode from which it was insulated. The spiral was of pure platinum wire $1 \mathrm{~mm}$. thick, and was heated by an electric current, its temperature being determined by means of its resistance. It was found that the absolute temperature could easily be kept constant to one part in a thousand, so that it did not vary more than one degree at the highest temperature investigated. The vacuum-tube containing the spiral and electrode was connected with a Töpler pump and McLeod gauge, so that the gas could be kept at any desired pressure.

The leak was measured by means of a quadrant electrometer. The wire was charged to any desired positive

* Communicated by the Physical Society : read June 12, 1903.

† Proc. Camb. Phil. Soc. xi. p. 286; Proc. Rò. Soc. lxxi. p. 415. 